\title{
Comic Strips to Accompany Science Museum Exhibits
}

\author{
Beom Sun Chung ${ }^{1}$, Eun-mi Park ${ }^{2}$, Sang-Hee Kim² ${ }^{2}$, Sook-kyoung Cho ${ }^{2} \&$ Min Suk Chung ${ }^{1}$ \\ ${ }^{1}$ Department of Anatomy, Ajou University School of Medicine, Suwon, Republic of Korea \\ ${ }^{2}$ Gwangju National Science Museum, Gwangju, Republic of Korea \\ Correspondence: Min Suk Chung, Department of Anatomy, Ajou University School of Medicine, 164 \\ Worldcup-ro, Suwon, 16499, Republic of Korea. Tel: 82-10-6474-1448. E-mail: dissect@ajou.ac.kr
}

Received: June 10, 2016

doi:10.5539/jel.v5n4p141
Accepted: August 23, $2016 \quad$ Online Published: September 22, 2016

URL: http://dx.doi.org/10.5539/jel.v5n4p141

\begin{abstract}
Science museums make the effort to create exhibits with amusing explanations. However, existing explanation signs with lengthy text are not appealing, and as such, visitors do not pay attention to them. In contrast, conspicuous comic strips composed of simple drawings and humors can attract science museum visitors. This study attempted to reveal whether comic strips contribute to science exhibitions. More than 20 comic strips were chosen that were associated with exhibits in a science museum. The individual episodes were printed out and placed beside the corresponding exhibits. A questionnaire was administered to museum visitors to evaluate the effects of the comic strips. Most visitors responded that the comic strips were helpful in understanding the exhibits and in familiarizing themselves with the science. Participants also described the comic strips' deficiencies which will be considered for future revisions. Comic strips are likely to enhance interest in and comprehension of science exhibitions. Furthermore, these strips are expected to enrich science museums in various ways such as establishing their uniqueness.
\end{abstract}

Keywords: cartoons, science, learning, museums, nonprofessional education

\section{Introduction}

In science museums (including natural science museums), exhibits are accompanied by signs to introduce their scientific backgrounds. However, existing explanations consisting of lengthy texts are not tempting, so that many visitors skip the signs when experiencing the exhibits.

One solution could be entertaining comic strips that are related to the exhibits. The museum visitors would pay attention to the comic strips, which are known to be beneficial in learning new and complex science concepts (Mathewson, 1999). After enjoying the humor in the strips, readers will be more interested in the exhibits and explanation signs.

The purpose of this study is to evaluate how comic strips contribute to science exhibitions. Twenty-three episodes of comic strips that were associated with the exhibits in a science museum were chosen from among the authors' works. The individual episodes were printed and placed beside the equivalent exhibits. A questionnaire was collected from 70 visitors who experienced both the comic strips and the exhibits.

\section{Method}

The corresponding author has illustrated the science comic strip "Dr. Scifun" (Kim et al., 2012) and the anatomy comic strip "Dr. Anatophil" (Park et al., 2011; Shin et al., 2013). At first, the comics were drawn in Korean (315 episodes on science, 775 on anatomy) (Hwang et al., 2005). Subsequently, they were translated into English (180 episodes on science, 451 on anatomy); during translation, the episodes containing the Korean language jokes were regretfully omitted. The full episodes in both languages have been distributed free of charge through a website (anatomy.co.kr).

The plan to display the comic strips interested a Korean science museum, the Gwangju National Science Museum (Lucerium). After establishing the consensus, all science exhibits and explanation signs in the museum were examined in order to select the appropriate strips, science or anatomy. If there were no suitable episodes already, we created new strips. A total of 23 episodes were printed in color and displayed next to the corresponding exhibits (Figure 1). 


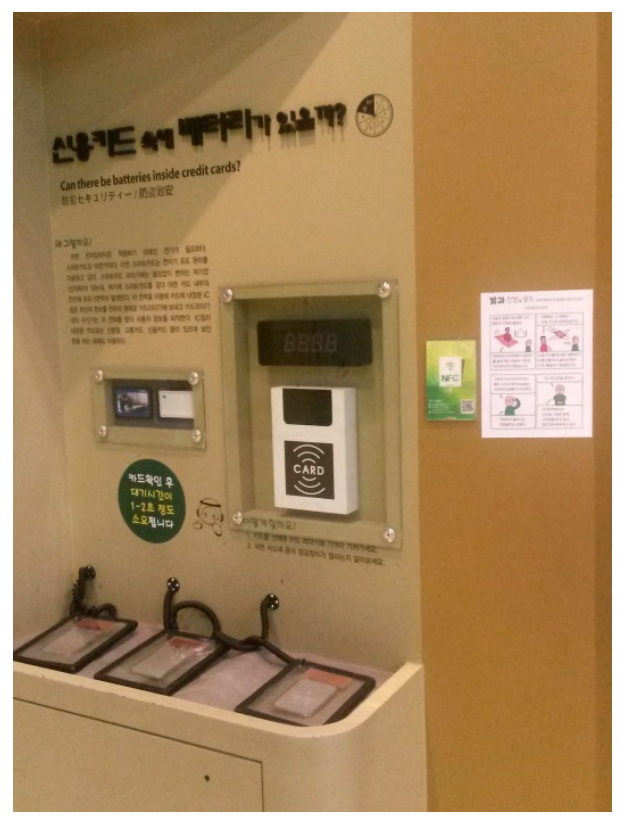

Figure 1. Comic strip (right) beside a relevant exhibit and its explanation sign (in Korean)

At the museum, visitors who had seen the comic strips were asked to answer the questionnaire. Specifically, the volunteer respondents selected the most interesting and most instructive episodes among the 23. Using multiple-choice, respondents recorded how helpful the strips were in understanding the exhibits and familiarizing themselves with science (Table 1). Participants then used an open-ended question to describe the shortcomings of the comic strips. The participants were Koreans, so all the exhibitions, comics, and questionnaire were in Korean (Figure 1). The materials were translated into English for this report.

Table 1. Contributions of the displayed comic strips in the science museum

\begin{tabular}{llllll}
\hline & $\begin{array}{l}\text { Absolutely } \\
\text { no }\end{array}$ & $\begin{array}{l}\text { Relatively } \\
\text { no }\end{array}$ & $\begin{array}{l}\text { Relatively } \\
\text { yes }\end{array}$ & $\begin{array}{l}\text { Absolutely } \\
\text { yes }\end{array}$ & Total \\
\hline Helpful in understanding the exhibits & $1.5 \%$ & $7.4 \%$ & $50.0 \%$ & $41.2 \%$ & $100.0 \%(68$ cases) \\
Helpful in familiarity with science & $1.4 \%$ & $7.0 \%$ & $43.7 \%$ & $47.9 \%$ & $100.0 \%$ (71 cases) \\
\hline
\end{tabular}

\section{Results}

Seventy visitors to the science museum participated in this survey. The majority of subjects were elementary school students (6-12 years old) (51.4\%) and their parents (37.1\%); the remainder were middle school, high school, and college students (12-24 years old; $11.4 \%$ ). There were no notable differences in the results by age or gender (31 male, 39 female).

Based on the participants' responses, the most interesting and most instructive episode was the one titled "Why is the fish's back so blue?" (Figure 2). The second most interesting episode was "Beyond visible ray" (Figure 3), and the second most instructive one was "3D" (Figure 4). 
Why is fish's back so blue?
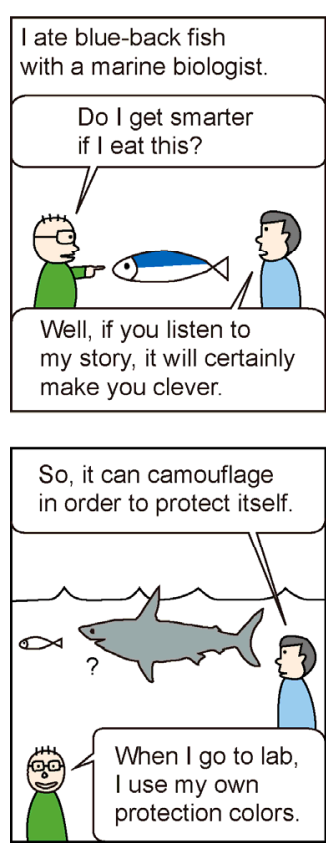

The fish with a blue back lives in a shallow surface.

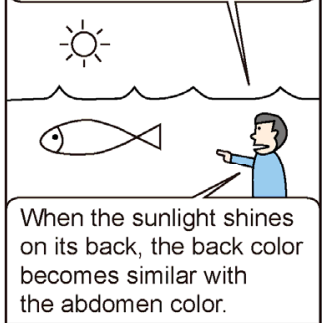

So I can easily spot

several students

fooling around

during their procedures.

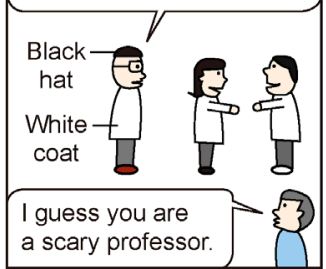

Figure 2. The most interesting and most instructive episode chosen by the science museum visitors

Beyond visible ray
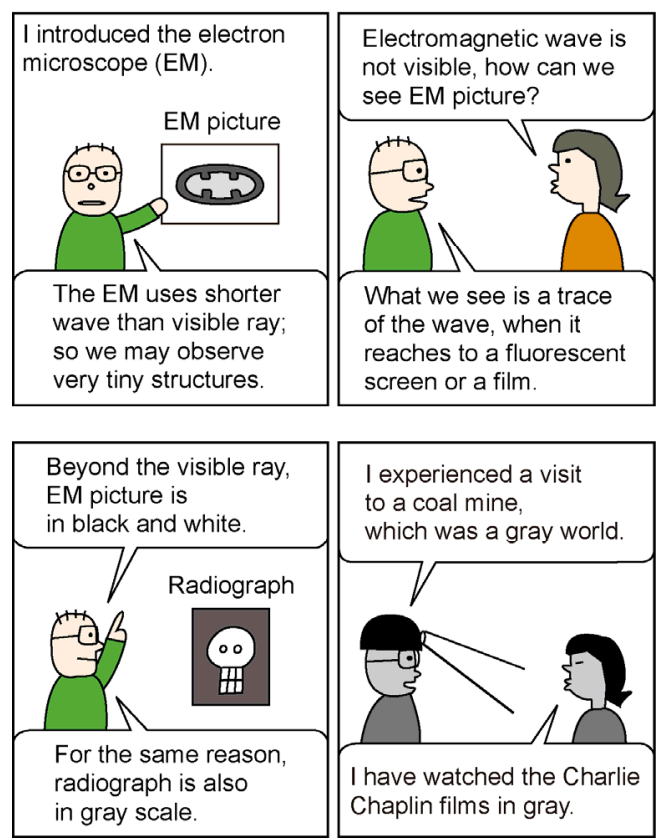

Figure 3. The second most interesting episode chosen by the science museum visitors 
$3 \mathrm{D}$

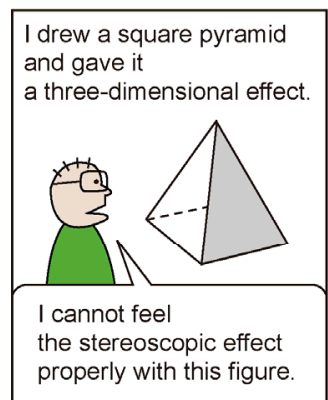

So I drew these square pyramids as shown below.

and gave it
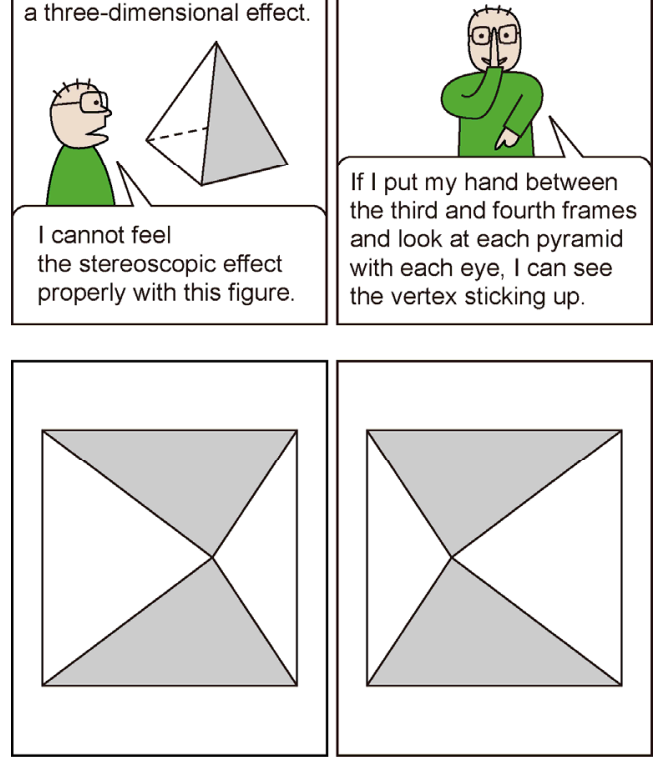

Figure 4. The second most instructive episode chosen by the science museum visitors

Most subjects (91.2\%) responded that the comic strips were helpful in understanding the exhibits. Moreover, $91.6 \%$ of them agreed that the comic strips were helpful in familiarizing themselves with the science (Table 1). However, respondents also commented on the deficiencies and potential improvements for the comic strips (Table 2).

Table 2. Free descriptions about the drawbacks of the displayed comic strips in a science museum

\footnotetext{
Four frames are too short to contain an appropriate story.

The stories in the comic strips need more examples or metaphors about the topic.

The stories are difficult and not funny.

The figures are extremely simple; they need to be more sophisticated.

The text in each frame is too lengthy for comic strips.
}

\section{Discussion}

It is desirable for science museum visitors to enjoy science rather than study it. In the case of young visitors, they just need to recognize how the science entertains them; then, the youngs will be willing to major in science and devote themselves to the subject in the future (She, 1995; Kim et al., 2012). It can be said that the most important function of science museums is to interest children and adolescents, which is why every science museum aims to present pleasing exhibits with amusing explanation signs (Boisvert \& Slez, 1995; Rennie \& McClafferty, 1995).

In the last decade, authors grew interested in using comic strips to make complex scientific knowledge enjoyable and easy to understand (Rota \& Izquierdo, 2003). The comics relate the knowledge to everyday happenings to make scientific concepts familiar to readers. This connection of knowledge to the reader's prior experience improves comprehension and remembrance (Alesandrini, 1984). The comic strips' two sources of information, which are visual and verbal, produce a synergistic effect in learning (Liu, 2004).

In science museums, the explanation signs and comic strips might influence each other (Figure 1). In the present study, some explanations were used as the source of the strips. Reversely, by referring to the comic strips, the explanations could be refined to be funnier and more comprehensible. Without doubt, this is advantageous in enriching science museum exhibits. 
Using comic strips, these museums can reflect their identities and highlight important points. As with other types of museums (history, art), each science museum has its own characteristics. The unique museums earn solid reputations and then attract visitors from beyond their local areas, including other countries (Hudson, 1987). It is difficult for museums to distinguish themselves solely with science exhibits. A possible solution is comic strips, which offer more personality than other multimedia data (Tatalovic, 2009). The main character of the comics may be recognized as the mascot of the museum.

The comic strips that are displayed in science museums can be readily digitalized and added to museum homepages. Then, people who see the comics will visit the museums to experience the on-site comic strips and the related exhibitions. Thus, comic strips can play a publicizing role for science museums.

For interested museums, the authors kindly suggest the following. At the initial stage, museums can use our existing comic strips, on the website (anatomy.co.kr); there, hundreds of English episodes on science and anatomy are available. Museums can pick the appropriate strips for their needs and request the original Adobe Illustrator (AI) files from the authors. We only seek authorship credit when the strips are displayed, but not financial reward. The presented AI files comprising vector lines can be easily modified in Illustrator CS6 version 16 (Adobe Systems, Inc., San Jose, CA, USA) and clearly printed in large scale. Of course, the writing can be polished or translated into other languages.

The displayed comic strips can be revised on the basis of visitor criticism. For example, when the present study was launched, we felt that four-framed comic strips would be perfect for science museums. It was thought that one frame would be insufficient to tell a story but that more than four would be boring. However, on the questionnaire, some volunteers wished more frames, so we recognized that long comics were a choice (Kim et al., 2017). Similarly, upcoming requirements from readers will improve the comics (Table 2).

A strong point of the comic strips is that they can be easily upgraded in quality and quantity. As mentioned, museums can display the strips temporarily to assess visitor reactions, then amending or updating as appropriate. Their electronic displays can be changed even more easily (Sung et al., 2010). Additionally, the comic strips can be redrawn by professional cartoonists (Table 2). Comic strips do not cost as much as ordinary exhibits, but they offer a superior return on investment.

This research reveals that comic strips can effectively amuse and guide visitors in science museums. It is expected that museums will develop varieties of comics and influence each other in future.

\section{Acknowledgments}

This work was supported by the National Research Foundation of Korea (NRF) Grant funded by the Korean Government (MSIP) (No. 2015R1A5A7037630).

\section{References}

Alesandrini, K. L. (1984). Pictures and adult learning. Instructional Science, 13(1), 63-77. http://dx.doi.org/10.1007/BF00051841

Boisvert, D. L., \& Slez, B. J. (1995). The relationship between exhibit characteristics and learning-associated behaviors in a science museum discovery space. Science Education, 79(5), 503-518. http://dx.doi.org/10.1002/sce.3730790503

Hudson, K. (1987). Museums of Influence: Pioneers of the Last 200 Years. Cambridge: Cambridge.

Hwang, S. B., Chung, M. S., \& Park, J. S. (2005). Anatomy cartoon for common people. The Korean Journal of Anatomy, 38(5), 433-441.

Kim, D. H., Jang, H. G., Shin, D. S., Kim, S. J., Yoo, C. Y., \& Chung, M. S. (2012). Science comic strips. Journal of Education and Learning, 1(2), 65-71. http://dx.doi.org/10.5539/jel.v1n2p65

Kim, J., Chung, M. S., Jang, H. G., \& Chung, B. S. (2017). Anatomy learning comics. Anatomical Sciences Education (in press).

Liu, J. (2004). Effects of comic strips on L2 learners' reading comprehension. TESOL Quarterly, 38, 225-243. http://dx.doi.org/10.2307/3588379

Mathewson, J. H. (1999). Visual-spatial thinking. An aspect of science overlooked by educators. Science Education, $83(1)$, 33-54. http://dx.doi.org/10.1002/(SICI)1098-237X(199901)83:1\%3C33::AID-SCE2\%3E3.0.CO;2-Z 
Park, J. S., Kim, D. H., \& Chung, M. S. (2011). Anatomy comic strips. Anatomical Sciences Education, 4(5), 275-279. http://dx.doi.org/10.1002/ase.224

Rennie, L., \& McClafferty, T. (1995). Using visits to interactive science and technology centers, museums, aquaria, and zoos to promote learning in science. Journal of Science Teacher Education, 6(4), 175-185. http://dx.doi.org/10.1007/BF02614639

Rota, G., \& Izquierdo, J. (2003). "Comics" as a tool for teaching biotechnology in primary schools. Electronic Journal of Biotechnology, 6(2), 85-89. http://dx.doi.org/10.2225/vol6-issue2-fulltext-10

She, H. C. (1995). Elementary and middle school students' image of science and scientists related to current science textbooks in Taiwan. Journal of Science Education and Technology, 4(4), 283-294.

Shin, D. S., Kim, D. H., Park, J. S., Jang, H. G., \& Chung, M. S. (2013). Evaluation of anatomy comic strips for further production and applications. Anatomy \& Cell Biology, 46(3), 210-216. http://dx.doi.org/10.5115/acb.2013.46.3.210

Sung, Y. T., Chang, K. E., Hou, H. T., \& Chen, P. F. (2010). Designing an electronic guidebook for learning engagement in a museum of history. Computers in Human Behavior, 26(1), 74-83. http://dx.doi.org/10.1016/j.chb.2009.08.004

Tatalovic, M. (2009). Science comics as tools for science education and communication: A brief, exploratory study. Journal of Science Communication, 8(4), 1-17.

\section{Copyrights}

Copyright for this article is retained by the author(s), with first publication rights granted to the journal.

This is an open-access article distributed under the terms and conditions of the Creative Commons Attribution license (http://creativecommons.org/licenses/by/4.0/). 